\title{
COMPARISON OF THE METHODS OF DETERMINING SIF AND ERR AND THEIR APPLICATION TO RECYCLED MATERIALS
}

\author{
Ana Yanakieva, Gergana NiKOlova* \\ Institute of Mechanics, Bulgarian Academy of Sciences, \\ Acad. G. Bonchev. Str., Bl. 4, 1113 Sofia, Bulgaria \\ [Received: 19 August 2020. Accepted: 05 October 2020] \\ doi: 10.7546/JTAM.50.20.04.07
}

\begin{abstract}
The paper presents summation of the results of a number of our studies treating the mechanical behaviour of cracked structural elements and especially the methods of determining the Stress Intensity Factor (SIF) and the Energy Release Rate (ERR). Two possible methods are outlined - an analytical one (using the energy approach of fracture mechanics) and a computational one (using ANSYS). Comparison of the results found using the two methods is made. A parametric analysis with respect to initial crack and external loading is also performed. The basic idea of the study is to analyse structural elements fabricated from recycled material using respective data published in literature.
\end{abstract}

KEY WORDS: SIF, ERR, FEM, Cracked elements.

\section{INTRODUCTION}

The main principle of Fracture Mechanics is that unstable fracture occurs when the Stress Intensity Factor (SIF) reaches a critical value $K_{I C}$. The critical SIF $\left(K_{I C}\right)$ represents the inherent ability of a material to withstand given stress [1,2]. In linear elastic fracture mechanics, the important parameters in use are the various modes of SIF. Several methods have been proposed to determine SIF and ERR in Mode I. These are a displacement extrapolation near the crack tip, the J-integral, the energy domain integral etc. [3,4]. We use two methods in the present study - analytical (using the energy approach of fracture mechanics) and computational (using ANSYS). Thus, we determine SIF and ERR regarding structural elements fabricated from materials whose mechanical characteristics are taken from literature [5-7].

\section{Design of THE Model}

\subsection{MATERIAL CHARACTERISTIC, GEOMETRY, FINITE ELEMENT (FE) MESH}

The geometrical model presents a rectangular plate with unit thickness, length $l$ and width $h$. Plane strain conditions are assumed (Fig. 1a), Table $1[3,7]$.

Due to symmetry reasons only half of the plate is modelled. As only half of the geometry is modelled, symmetry boundary condition should be applied on the

\footnotetext{
${ }^{*}$ Corresponding author e-mail: gery@imbm.bas.bg
} 


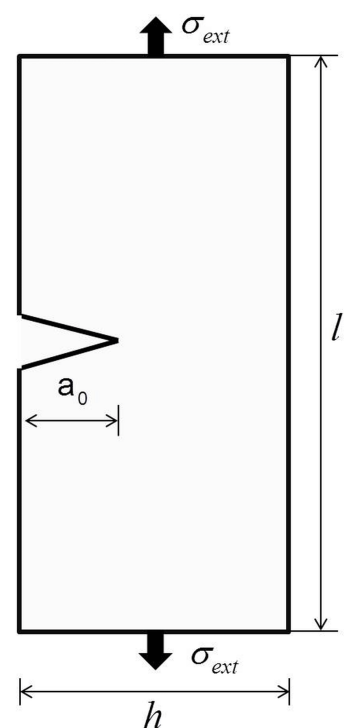

(a)

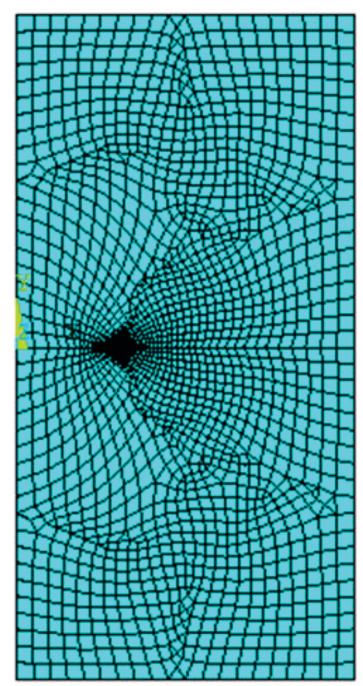

(b)

Fig. 1: Model of a rectangular plate with a single edge crack: (a) geometrical model; (b) mesh model.

symmetry plane. The crack surface is not restricted in its movement in any direction that is no boundary condition should be applied to that line.

The cracked element is fabricated from a polyester recycled concrete composite (PRCC) whose mechanical characteristics are taken from [5], as well as from a material containing recycled coarse aggregate concrete (RCAC), whose mechanical characteristics are given in [6], Table 1.

The assumed loading $\sigma_{\text {ext }}$ is also presented in Table 1.

Table 1: Assumed material properties [5,6] and loading

\begin{tabular}{ccccc}
\hline \hline & & \multicolumn{3}{c}{ Properties } \\
& $E[\mathrm{MPa}]$ & $\nu$ & $K_{I C}\left[\mathrm{MPa} / \mathrm{m}^{2}\right]$ & $\sigma_{\text {ext }}[\mathrm{MPa}]$ \\
\hline PRCC & 11000 & 0.16 & 41.15 & $10-30$ \\
RCAC & 29000 & 0.34 & 1.25 & $0.3-4.0$ \\
\hline \hline
\end{tabular}

Table 2 gives the geometry involved - a rectangular plate with length $l$ and width $h$ where the initial crack length is $a_{0}$. The finite elements used to mesh the element are type PLANE82 of the ANSYS code (Fig. 1b). PLANE82 is a higher order version of the 2-D, four-node element [8]. 
Table 2: Geometry, length of initial cracks and FE mesh [3,7]

\begin{tabular}{cccc}
\hline \hline & & Properties & \\
& $l \times h[\mathrm{~m}]$ & $a_{0}[\mathrm{~m}]$ & FE mesh \\
\hline PRCC & $2 \times 1$ & $0.001 \div 0.550$ & \multirow{2}{*}{ PLANE82 (ANSYS) } \\
RCAC & $2 \times 025 \div 0.500$ & \\
\hline \hline
\end{tabular}

Figure 2 shows the nodes that have been selected in the crack vicinity for Path definition.

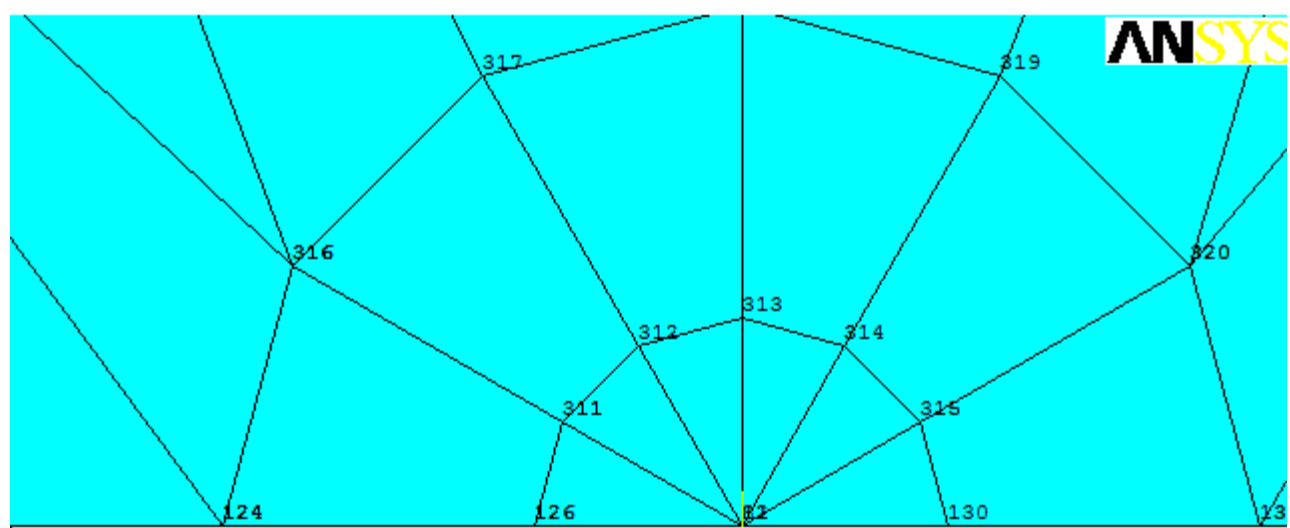

Fig. 2: Nodes $(82,126$ and 124) that have been chosen for Path definition.

\subsection{ANALYTICAL AND COMPUTATIONAL DETERMINATION OF SIF AND ERR}

Analytically, following the detailed coverage of the derivation of the linear elastic stress field around a crack tip, we will apply herein equations for pure Mode I to calculate the SIF and ERR:

$$
\begin{aligned}
K_{I}^{\mathrm{AM}}= & f\left(g, a_{0}\right) \sigma_{\mathrm{ext}} \sqrt{\pi a_{0}}, \\
f\left(g, a_{0}\right)= & 1.12-0.231\left(a_{0} / h\right)+10.55\left(a_{0} / h\right)^{2} \\
& -21.72\left(a_{0} / h\right)^{3}+30.39\left(a_{0} / h\right)^{4},
\end{aligned}
$$

where $f\left(g, a_{0}\right)$ is a non-dimensional configuration factor that depends on plate geometry and crack length.

The relation between SIF and ERR during crack growth, introduced by Griffith, is:

$$
G_{I}^{\mathrm{AM}}=\frac{\left(K_{I}^{\mathrm{AM}}\right)^{2}}{E}=\frac{\left(f\left(a_{0}, h\right) \sigma_{\mathrm{ext}} \sqrt{\pi a_{0}}\right)^{2}}{E} .
$$


Considering a purely elastic material, as in our case, the $J$-integral is equivalent to ERR. Hence, a critical value exists $-J=J_{C}$ (material constant), similar to $G_{I C}$. Then, we have

$$
J=G_{I}=\frac{K_{I}^{2}}{E^{\prime}}
$$

where $E^{\prime}=E$ in plane stress and $E^{\prime}=E /\left(1-\nu^{2}\right)$ in plane strain [9].

The analytical value of SIF for an edge crack element from PRCC with initial length of the crack $a_{0}=0.25 \mathrm{~m}$ and loading $\sigma_{\text {ext }}=30 \mathrm{MPa}$ is $K^{A M}=$ $39.91 \mathrm{MPa} / \mathrm{m}^{2}$ (an example only).

Consider an element fabricated from RCAC with initial length $a_{0}=0.25 \mathrm{~m}$ and subjected to tension equivalent to $\sigma_{\text {ext }}=0.94 \mathrm{MPa}$. Then, SIF and ERR are found analytically in accordance with the linear mechanics of fracture of composite materials, and their values are $K_{I C}^{A M}=1.25 \mathrm{MPa} / \mathrm{m}^{2}$ and $G_{I C}^{A M}=5.39 \times 10^{-5} \mathrm{MPa} . \mathrm{m}$.

The predicted value of SIF for the crack propagation problem (pure Mode I) applying linear elastic fracture analysis via FEM (computational method) is presented in the following Fig. 3.

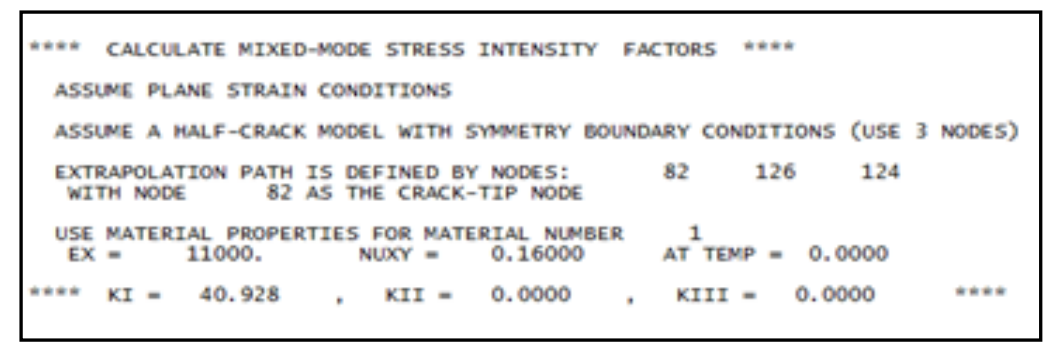

Fig. 3: SIF value using ANSYS code (an example).

The value of SIF (an example) obtained by using the ANSYS code for an edge crack composite with initial length of the crack $a_{0}=0.25 \mathrm{~m}$ and loading $\sigma_{\text {ext }}=$ $30 \mathrm{MPa}$ is $K_{I C}^{F E M}=40.93 \mathrm{MPa} / \mathrm{m}^{2}$.

Figure 4 provides the value $J=G_{I}=5.24 \times 10^{-5}$ MPa.m for a specified PATH. The results are found using the ANSYS code and valid for a crack with initial length $a_{0}=0.025 \mathrm{~m}$ and loading equivalent to $\sigma_{\text {ext }}=0.94 \mathrm{MPa}$ (identical to the one involved in the analytical example).

The equations (4), (5) and (6) show the verification of the results obtained by an analytical and a computational determination of SIF

$$
\frac{K_{I}^{\mathrm{FEM}}-K_{I}^{\mathrm{AM}}}{K_{I}^{\mathrm{FEM}}} \%=\frac{40.93-39.91}{40.93} \%=2.49 \%,
$$




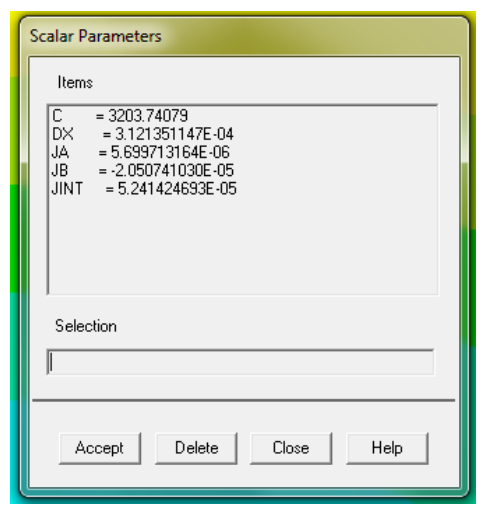

Fig. 4: $J$-integral value for a chosen PATH found using the ANSYS code.

$$
\begin{aligned}
& \frac{K_{I C}^{\mathrm{FEM}}-K_{I C}^{\mathrm{Exp}}}{K_{I C}^{\mathrm{FEM}}}=\frac{1.28-1.25}{1.28}=2.3 \%<5 \%, \\
& \frac{G_{I C}^{\mathrm{AM}}-G_{I C}^{\mathrm{FEM}}}{G_{I C}^{\mathrm{AM}}}=\frac{5.39 \times 10^{-5}-5.24 \times 10^{-5}}{5.39 \times 10^{-5}}=2.8 \%<5 \% .
\end{aligned}
$$

Very good agreement between the two methods is established (less than 5\%).

Having generated an adequate numerical model, we performed simulations considering different values of the external load $\sigma_{\text {ext }}=10 \div 30 \mathrm{MPa}$. The results are plotted in Fig. 5 providing a very good agreement between the two methods.

For small values of the external load we obtained almost $100 \%$ coincidences between the analytical and the computational results. For larger loads however the error slightly increased. Yet, it is still within the prescribed limits remaining lower than

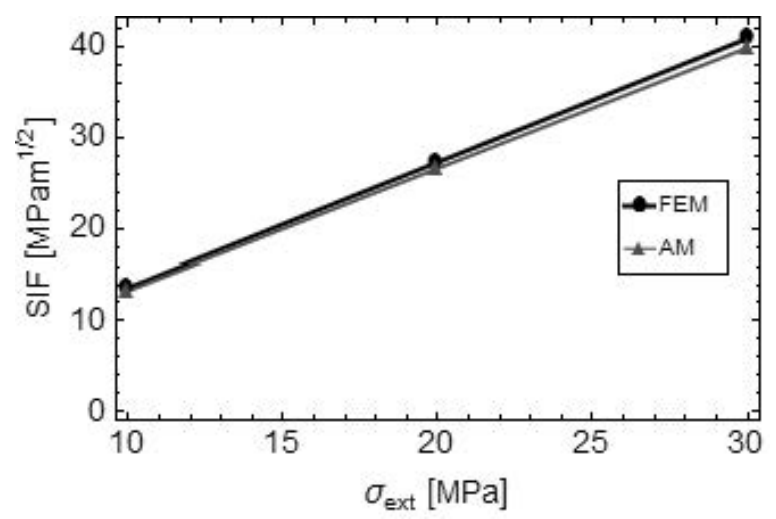

Fig. 5: FEM and AM results for three different loads for material PRCC. 
5\%. After the verification of the computational model the results for two elements fabricated from different materials - PRCC and RCAC are presented in Tables 3-6. The first value of SIF is analytically found while the second one is computed.

Table 3: PRCC - Analytical and Computational results for SIF $\left(K_{I}\left[\mathrm{MPa} / \mathrm{m}^{2}\right]\right)$

\begin{tabular}{cccc}
\hline \hline \multirow{2}{*}{$a_{0}[\mathrm{~m}]$} & 10 & $\sigma_{\text {ext }}[\mathrm{MPa}]$ & 30 \\
\hline \multirow{2}{*}{0.001} & 0.630 & 20 & 1.880 \\
& 0.650 & 1.260 & 1.930 \\
0.200 & 10.870 & 1.290 & 32.590 \\
& 11.150 & 21.730 & 33.430 \\
0.250 & 13.300 & 22.290 & 39.910 \\
& 13.643 & 26.600 & 40.930 \\
0.330 & 18.050 & 27.285 & $\mathbf{5 4 . 1 4 0}$ \\
& 18.510 & 36.090 & $\mathbf{5 5 . 5 3 0}$ \\
0.500 & 35.420 & 37.020 & $\mathrm{x}$ \\
& 36.330 & $\mathbf{7 0 . 8 5 0}$ & $\mathrm{x}$ \\
\multirow{2}{*}{0.550} & $\mathbf{4 4 . 0 5 0}$ & $\mathbf{7 2 . 6 7 0}$ & $\mathrm{x}$ \\
& $\mathbf{4 5 . 1 8 0}$ & $\mathrm{x}$ & $\mathrm{x}$ \\
\hline \hline
\end{tabular}

Table 4: PRCC - Analytical and Computational results for ERR ( $\left.G_{I}[\mathrm{MPa} . \mathrm{m}]\right)$

\begin{tabular}{|c|c|c|c|}
\hline \multirow[b]{2}{*}{$a_{0}[\mathrm{~m}]$} & \multicolumn{3}{|c|}{$\overline{\sigma_{\text {ext }}[\mathrm{MPa}]}$} \\
\hline & 10 & 20 & 30 \\
\hline 0.001 & $\begin{array}{l}3.29 \times 10^{-5} \\
3.20 \times 10^{-5}\end{array}$ & $\begin{array}{l}1.34 \times 10^{-4} \\
1.30 \times 10^{-4}\end{array}$ & $\begin{array}{l}2.98 \times 10^{-4} \\
2.90 \times 10^{-4}\end{array}$ \\
\hline 0.200 & $\begin{array}{l}9.77 \times 10^{-3} \\
9.50 \times 10^{-3}\end{array}$ & $\begin{array}{l}3.91 \times 10^{-2} \\
3.80 \times 10^{-2}\end{array}$ & $\begin{array}{l}8.74 \times 10^{-2} \\
8.50 \times 10^{-2}\end{array}$ \\
\hline 0.250 & $\begin{array}{l}1.44 \times 10^{-2} \\
1.40 \times 10^{-2}\end{array}$ & $\begin{array}{l}5.86 \times 10^{-2} \\
5.70 \times 10^{-2}\end{array}$ & $\begin{array}{l}1.34 \times 10^{-1} \\
1.30 \times 10^{-1}\end{array}$ \\
\hline 0.330 & $\begin{array}{l}2.67 \times 10^{-2} \\
2.60 \times 10^{-2}\end{array}$ & $\begin{array}{l}1.03 \times 10^{-1} \\
1.00 \times 10^{-1}\end{array}$ & $\begin{array}{l}2.47 \times 10^{-1} \\
2.40 \times 10^{-1}\end{array}$ \\
\hline 0.500 & $\begin{array}{l}1.03 \times 10^{-1} \\
1.00 \times 10^{-1}\end{array}$ & $\begin{array}{l}4.12 \times 10^{-1} \\
4.00 \times 10^{-1}\end{array}$ & $\begin{array}{l}\mathrm{x} \\
\mathrm{x}\end{array}$ \\
\hline 0.550 & $\begin{array}{l}1.65 \times 10^{-1} \\
1.60 \times 10^{-1}\end{array}$ & $\begin{array}{l}\mathrm{x} \\
\mathrm{x}\end{array}$ & $\begin{array}{l}\mathrm{x} \\
\mathrm{x}\end{array}$ \\
\hline
\end{tabular}


Table 5: RCAC - Analytical and Computational results for SIF $\left(K_{I}\left[\mathrm{MPa} / \mathrm{m}^{2}\right]\right)$

\begin{tabular}{cccc}
\hline \hline & & $\sigma_{\text {ext }}[\mathrm{MPa}]$ & \\
$a_{0}[\mathrm{~m}]$ & 0.35 & 0.94 & 3.98 \\
\hline \multirow{2}{*}{0.025} & 0.110 & 0.300 & $\mathbf{1 . 2 5}$ \\
& 0.112 & 0.310 & $\mathbf{1 . 2 8}$ \\
0.250 & 0.470 & $\mathbf{1 . 2 5 0}$ & $\mathrm{x}$ \\
& 0.480 & $\mathbf{1 . 2 8 0}$ & $\mathrm{x}$ \\
\multirow{2}{*}{0.500} & $\mathbf{1 . 2 5 0}$ & $\mathrm{x}$ & $\mathrm{x}$ \\
& $\mathbf{1 . 2 8 0}$ & $\mathrm{x}$ & $\mathrm{x}$ \\
\hline \hline
\end{tabular}

Table 6: RCAC - Analytical and Computational results for ERR $\left(G_{I}[\mathrm{MPa} . \mathrm{m}]\right)$

\begin{tabular}{cccc}
\hline \hline \multirow{2}{*}{$a_{0}[\mathrm{~m}]$} & 0.35 & $\sigma_{\text {ext }}[\mathrm{MPa}]$ & 0.94 \\
\hline \multirow{2}{*}{0.025} & $4.17 \times 10^{-7}$ & $3.10 \times 10^{-6}$ & $\mathbf{5 . 3 9} \times \mathbf{1 0}^{-\mathbf{5}}$ \\
& $4.15 \times 10^{-7}$ & $3.09 \times 10^{-6}$ & $\mathbf{5 . 2 4} \times \mathbf{1 0}^{-\mathbf{5}}$ \\
0.250 & $7.60 \times 10^{-6}$ & $\mathbf{5 . 3 9} \times \mathbf{1 0}^{-\mathbf{5}}$ & $\mathrm{x}$ \\
& $7.57 \times 10^{-6}$ & $\mathbf{5 . 2 4} \times \mathbf{1 0}^{-5}$ & $\mathrm{x}$ \\
0.500 & $\mathbf{5 . 3 9} \times \mathbf{1 0}^{-\mathbf{5}}$ & $\mathrm{x}$ & $\mathrm{x}$ \\
& $\mathbf{5 . 2 4} \times \mathbf{1 0}^{-\mathbf{5}}$ & $\mathrm{x}$ & $\mathrm{x}$ \\
\hline \hline
\end{tabular}

The results in Bold script for the Stress Intensity Factor and the Energy Release Rate in Tables $3-6$ show values of SIF and ERR, which are equal to or larger than the critical values $K_{I C}$ and $G_{I C}$ characterizing the specific material. Based on those characteristics, we calculate the respective critical value of the initial crack length $\left(a_{I C}\right)$ and that of the external loading $\left(\sigma_{\text {ext }}\right)$ considering recycled materials of the type PRCC and RCAC.

\section{For PRCC:}

$$
\begin{array}{llll}
\sigma_{\text {ext }}=10 \mathrm{MPa} ; & K_{I C}=41.15 \mathrm{MPa} / \mathrm{m}^{2} ; & a_{I C}=0.530 \mathrm{~m} \\
\sigma_{\text {ext }}=20 \mathrm{MPa} ; & K_{I C}=41.15 \mathrm{MPa} / \mathrm{m}^{2} ; & a_{I C}=0.364 \mathrm{~m} \\
\sigma_{\text {ext }}=30 \mathrm{MPa} ; & K_{I C}=41.15 \mathrm{MPa} / \mathrm{m}^{2} ; & a_{I C}=0.257 \mathrm{~m} \\
\sigma_{\text {ext }}=10 \mathrm{MPa} ; & G_{I C}=0.14 \mathrm{MPa} . \mathrm{m} ; & a_{I C}=0.530 \mathrm{~m} \\
\sigma_{\text {ext }}=20 \mathrm{MPa} ; & G_{I C}=0.14 \mathrm{MPa} . \mathrm{m} ; & a_{I C}=0.364 \mathrm{~m} \\
\sigma_{\text {ext }}=30 \mathrm{MPa} ; & G_{I C}=0.14 \mathrm{MPa} . \mathrm{m} ; & a_{I C}=0.257 \mathrm{~m}
\end{array}
$$




\section{For RCAC:}

$$
\begin{aligned}
& \sigma_{\text {ext }}=0.35 \mathrm{MPa} ; \quad K_{I C}=1.25 \mathrm{MPa} / \mathrm{m}^{2} ; \quad a_{I C}=0.500 \mathrm{~m} \\
& \sigma_{\text {ext }}=0.94 \mathrm{MPa} ; \quad K_{I C}=1.25 \mathrm{MPa} / \mathrm{m}^{2} ; \quad a_{I C}=0.250 \mathrm{~m} \\
& \sigma_{\text {ext }}=3.98 \mathrm{MPa} ; \quad K_{I C}=1.25 \mathrm{MPa} / \mathrm{m}^{2} ; \quad a_{I C}=0.025 \mathrm{~m} \\
& \sigma_{\mathrm{ext}}=0.35 \mathrm{MPa} ; \quad G_{I C}=5.39 \times 10^{-5} \mathrm{MPa} . \mathrm{m} ; \quad a_{I C}=0.500 \mathrm{~m} \\
& \sigma_{\text {ext }}=0.94 \mathrm{MPa} ; \quad G_{I C}=5.39 \times 10^{-5} \mathrm{MPa} . \mathrm{m} ; \quad a_{I C}=0.250 \mathrm{~m} \\
& \sigma_{\text {ext }}=3.98 \mathrm{MPa} ; \quad G_{I C}=5.39 \times 10^{-5} \mathrm{MPa} . \mathrm{m} ; \quad a_{I C}=0.025 \mathrm{~m}
\end{aligned}
$$

\section{CONCLUSion}

Special programs within MATHEMATICA and ANSYS environment are designed to determine the Stress Intensity Factor and the Energy Release Rate. The values of SIF and ERR are found for structural elements fabricated from recycled materials.

Verification of the two methods is made using specific values of the initial crack length and the external loading. Tables $3-6$ present the results of the two methods.

The critical value of the external loading and that of the initial crack length are found, and subsequent critical values of the Stress Intensity Factor and the Energy Release Rate are attained regarding the different materials of the elements.

\section{REFERENCES}

[1] A.A. Griffith (1920) The Phenomena of Rupture and Flow in Solids. Philosophical Transactions of the Royal Society of London. Series A 221 163-198.

[2] G.R. IRWIN (1957) Analysis of Stresses and Strains near the End of a Crack Traversing a Plate. Journal of Applied Mechanics 24 361-364.

[3] A. Yanakieva, G. Nikolova (2015) Determination of the stress intensity factor of RPCC element with edge crack using FEM and analytical calculations. In: Proceedings of XV International scientific conference VSU'2015 1 67-72.

[4] K. Kazakov (2010) "Finite Element Method for Structural Modelling". Prof. M. Drinov, Academic Publishing House, Sofia.

[5] L. Czarnecki, A. Garbacz, P. Likowski, J. Clifton (1999) Optimization of Polymer Concrete Composite: Final Report (NISTIR 6361), 63.

[6] V. Cervantes, J. Roesler, A. Bordelon (2007) Fracture and Drying Shrinkage Properties of Concrete Containing Recycled Concrete Aggregate. (Tech note No: 34, Centre of excellent for airport technology).

[7] A. Yanakieva (2015) Stress Determination In a Cracked Bi-Material Element Using The LEFM Energy Approach. International Journal of Mechanical and Production Engineering 3(11) 47-52.

[8] ANSYS code Theory and Reference Manual (2009).

[9] G. Gospodin (1997) "Introduction in Computational fracture Mechanics". (Part I, UACG, Sofia). 